\title{
Building blocks for social-ecological transformations: identifying and building on governance successes for small-scale fisheries
}

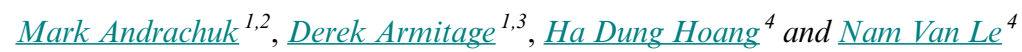

\begin{abstract}
We introduce building blocks as an approach to assess deliberative transformation pathways in linked systems of people and nature (i.e., small-scale fishery systems). In doing so, we address a knowledge gap about the maintenance and replication of governance processes that support transformative change, with a particular focus on small-scale fisheries that are facing ecological decline. Recent introduction of comanaged territorial use rights for small-scale fishers in the Cau Hai Lagoon, Vietnam has shown promise for alleviating ecological impacts from overfishing and reduced conflicts among fishers. We use this setting to inductively identify building blocks in two case study sites, and highlight the lessons for replicating successes in similar small-scale coastal fisheries. The investigation revealed five building blocks that were instrumental to success in the two case study communities: fisher approval of ecological conservation, cooperation among fishers, support from local government, secure funding, and effective leadership. These findings demonstrate site-level specificity of what governance attributes are already contributing to more durable and transformative change, and how these attributes can be augmented in other communities in the Cau Hai Lagoon. Key lessons for governance of transformations are that (1) building blocks do not need to be identical from case to case, and (2) further consideration needs to be given to how building blocks may nest or fit together. Our research contributes to a relatively new body of literature on deliberative transformations and offers guidance on a way to support and enhance transformations of small-scale fisheries.
\end{abstract}

Key Words: deliberative transformations; small-scale fisheries; territorial use rights for fishers; transformation pathways

\section{INTRODUCTION}

We examine what it means to support and enhance processes of social-ecological transformations for coastal small-scale fisheries (SSF). In particular, we are interested in examining how to proactively address persistent challenges facing SSF. These challenges include social inequality and poverty, unclear tenure and property rights, overcapacity, and lack of comprehensive policies that address the well-being needs of small-scale fishers (O'Brien 2012, Pomeroy 2012, Nayak and Berkes 2014, Cinner and McClanahan 2015, Jentoft and Chuenpagdee 2015, Saunders et al. 2016). The concept of deliberative social-ecological transformations implies the creation of fundamentally different pathways through which societies make decisions about, and interact with, fishery resources.

To facilitate transformations in small-scale fishery contexts, there is an imperative to improve our understanding of, and learn how to shape, transformative processes ex ante (see Moore et al. 2014, Olsson et al. 2014, Patterson et al. 2017). For example, as part of their framework to analyze deliberative transformations, Moore et al. (2014) cite the importance of adopting innovations that are successful in experimental stages (uptake and replication). This involves learning about what is working in particular places and contexts and "scaling out" to similar contexts. However, further context-specific guidance is needed on how such scaling out can be achieved, particularly in places where there have been successful fisheries governance innovations.

We introduce "building blocks for transformations" as a heuristic to study opportunities to build on early successes in small-scale fisheries. Identifying and learning about what is already working in situ can be valuable for replicating conditions that have led to early signs of transformations. We apply this approach in Vietnam where a governance transformation in a small-scale fishery is thought to be underway (Armitage et al. 2011, Andrachuk and Armitage 2015). We examine early site-specific or localized successes to identify building blocks that may be replicated across the system more broadly.

Transformations research is limited in its ability to perceive and confirm the occurrence of social-ecological transformations only in hindsight (Carpenter et al. 2005). This research brings a novel approach to the transformations literature by highlighting how it may be possible to focus on small successes as forward-looking research instead of relying solely on historical cases or focusing on barriers and constraints (Patterson et al. 2017). In doing so, we aim to understand what occurs along transformation pathways by focusing on the aspects of governance in small-scale fisheries that can be maintained and replicated.

We bring together two bodies of literature to define core attributes of building blocks for social-ecological transformation, and to develop the criteria upon which to assess their potential: (1) an emerging body of literature on governance transformations in small-scale fisheries, and (2) literature on processes of, and supporting conditions for, transformations. Our inductive assessment proceeds from a description of the transition to collective property rights and comanagement in the Cau Hai Lagoon, Vietnam and indepth consideration of what is working in two subcases. Synthesis of case-specific building blocks is followed by consideration of what strategies and aspects may be replicated for other communities. The lessons from this research will be of interest for replicating successes within the Cau Hai Lagoon and for other SSF that are undergoing transformative governance changes (and further supports insights from Armitage et al. 2017).

${ }^{1}$ Environmental Change and Governance Group, University of Waterloo, ${ }^{2}$ Department of Geography and Environmental Management, University of Waterloo, ${ }^{3}$ School of Environment, Resources and Sustainability, University of Waterloo, ${ }^{4}$ Hue University of Agriculture and Forestry 


\section{LITERATURE REVIEW AND CONCEPTUAL FRAMEWORK}

\section{Governance transformations in small-scale fisheries}

Small-scale fisheries research has considered both unintentional and deliberative transformations. Unintentional transformations - sometimes framed as regime shifts - are typically viewed in relation to drivers of change (e.g., impacts of climate change and technological innovations) and the ways that they shift community well-being, power, and property rights (e.g., Bennessaiah and Sengupta 2014, Bush and Marschke 2014, Nayak and Berkes 2014).

Deliberative transformations in SSF are often framed around transitions to comanagement or other collaborative and ecosystem-based management arrangements. Cinner et al. (2012) used several transitions concepts (drivers of change, institutional arrangements, institutional fit, actor interactions, and adaptive management) to assess movement toward decentralization for comanagement in Kenya, Tanzania, and Madagascar. Gelcich et al. (2010) pointed to the importance of ecological crisis and political turmoil for opening a critical window of opportunity in a Chilean fishery, but that a governance transformation was seeded by a novel application of marine tenure rights for artisanal fishers. Chuenpagdee and Jentoft (2007) demonstrated that the combination of actors who initiate comanagement (i.e., government, local entrepreneurs, donor agencies, researchers, or environmental groups) can influence the effectiveness of implementation. The role of social networks has also been studied in various contexts and has helped illuminate the ways that social capital and interpersonal relationships influence outcomes of governance transformations, such as enforcement and fisher participation (e.g., Crona and Bodin 2010, Alexander et al. 2015).

Taken together, SSF literature emphasizes the importance of sitelevel understanding of particular places and contexts that influence social and ecological systems (Allison and Ellis 2001, Pomeroy 2012, Hauzer et al. 2013, Weeratunge et al. 2014, Fabinyi et al. 2015). The SSF literature also shows how governance transformations require appropriate legal settings, leadership, social pressures, multi-actor and multilevel relationships, and take advantage of windows of opportunity with innovative problem solving (see also Nasuchon and Charles 2010, Benessaiah and Sengupta 2014, Blythe 2014, Frey and Berkes 2014, Cinner and McClanahan 2015). However, there remains an opportunity in this literature to better identify points of departure with which to "scale out" successful experiences.

\section{Transformations processes}

We align our thinking with Moore et al. (2014) in that the outcomes of transformations are shaped by both the agency of actors and underlying social and biophysical conditions. Path dependence and feedbacks tend to reinforce existing structures and dimensions of politics, power imbalances, and contested values among actors (Avelino and Rotmans 2009, Heinmiller 2009, Pelling et al. 2015, Nayak et al. 2016). Actors may not "control" transformations but they do nudge toward their goals by resisting undesirable path dependencies or working to establish new norms and patterns of development (Moore et al. 2014). Hence, there is a need for bottom-up and top-down perspectives on how to foster meaningful and lasting changes.
Olsson et al. (2004, 2006) view transformations in terms of sequential phases: building toward, and preparing for, systems change; capitalizing on windows of opportunity; navigating messy transitions; and building resilience of new regimes. Within this area of research, social capital and social networks, multilevel interactions, institutional flexibility, experimentation and learning, and leadership have been identified among key factors for progressing through the phases of transformation (Hahn et al. 2006, Olsson et al. 2008, Rijke et al. 2013, Moore et al. 2014). A related line of research focuses on social innovation and the agency of key actors in leveraging and triggering changes in broader social-ecological systems (Westley et al. 2011, 2013). Social or technological innovations can be important to address power imbalances, challenge norms, or create disruptions and new opportunities (Olsson et al. 2006, Westley et al. 2011, Leach et al. 2012). We situate building blocks as part of a process of navigating the transition and building the new regime (see Olsson et al. 2004, 2010), where clear signals of potential transformation are in place at the local level but outcomes are still uncertain.

The transformation literature is useful for understanding highlevel and long-term processes but is more limited when seeking to devise practical site-level strategies to support and enhance potentially transformative initiatives. Accordingly, a number of researchers have turned their attention to assessing enabling and supporting conditions for transformations. Feola (2015) argued that since transformations are multifaceted and complex, it is helpful to have a variety of frameworks that address different aspects of transformations. Some research has questioned what combination of socio-economic and biophysical changes constitute social-ecological transformations (e.g., Ferguson et al. 2013, Moore et al. 2014, Andrachuk and Armitage 2015, Patterson et al. 2017), while other scholarship has focused specifically on governance conditions that are conducive to transformations (e.g., Leach et al. 2012, Burch et al. 2014, Pereira et al. 2015). Pereira et al. (2015) identified a set of principles for "safe operating space" that are seen as necessary for transformations to sustainability. Those principles are emancipation and empowerment, ensuring reflexivity, knowledge cocreation, transformative learning, and nurturing innovations (Pereira et al. 2015). These conditions are consistent with much of the literature. However, additional specificity is needed to inform local-level actions in an SSF context.

The motivation for introducing building blocks in this paper is to address the challenge of supporting and enabling transformations in progress in SSF. We do this by empirically identifying local successes within communities in the Cau Hai Lagoon, Vietnam, and analyzing opportunities to replicate those successes for other communities in the lagoon. We inductively identify building blocks that are relevant for this specific context.

\section{Building blocks for social-ecological transformations}

The metaphor of building blocks emphasizes the value of contextual specificity and empirical understanding of what has led to small, early successes for SSF transformations. We offer several guiding attributes, based on our review of SSF and transformations literature, that help scope what building blocks may look like. First, building blocks are local and relevant for particular places and times. Spatial and temporal boundaries are important due to variability in social, economic, political, and 
ecological systems. Emphasis is given to bottom-up perspectives, although recognition must be given to changes that can be topdown. A transformation need not have the same building blocks from place to place. Building blocks indicate how success was achieved in one place that may be useful in other similar contexts. Second, consideration should be given to a wide array of institutions, roles for key people, types of networks, technological or social innovations, management arrangements, knowledge, or values and perspectives (emphasized as different shapes in Fig. 1).

Fig. 1. Building blocks along a transformation pathway. This graphic representation emphasizes that it is more important to think about how building blocks may fit together rather than assuming a linear pathway. Several blocks together begin to build a pathway.

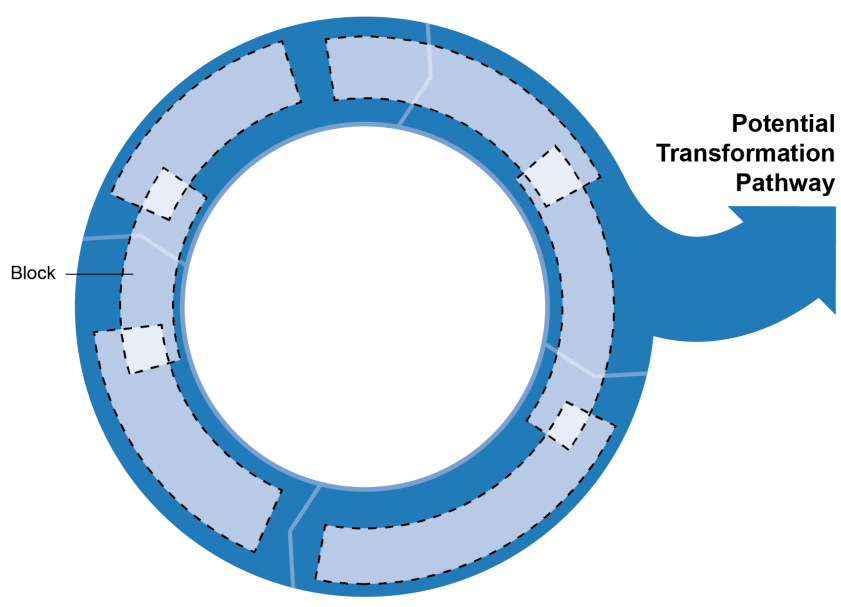

Third, building blocks are not static or linear. Building blocks are part of how transformation pathways are achieved, reflecting a normative vision of where people want to go. There is not a first step or specified sequence of actions, and what is needed may shift over time. Fourth, we envision building blocks as features that have been seeded as part of a new regime. We shift the focus away from barriers and constraints. Resistance against traps and lockins of an old regime are critically important but do not tell us how to move forward. Building blocks may feature empowerment, poverty reduction, and other pro-equity reforms as a new regime is taking shape. Lags and barriers are common for socialecological change due to path dependence. Building blocks, as a tool for intervention, are useful for moving beyond lags that may have stalled transformations.

We use the building blocks metaphor to help think about the local level and how communities are participating in - and drivingtransformative changes. Building blocks are distinguished from other frameworks for, and conceptualizations of, transformations (Feola 2015) by the emphasis on local-level, empirical research that specifically targets means of supporting deliberative transformations in progress. Existing transformations conceptualizations and frameworks do not always emphasize site-level guidance and policy development. Investigating a case that is potentially transformative and in progress (Armitage et al. 2011, Andrachuk and Armitage 2015) offers a unique opportunity to learn how it may become actually transformative. The value added from building blocks is thinking about how they nest or fit together. One block is insufficient, but several together start to build strength for a transformation, allowing for an assessment of the niche conditions and processes that can be replicated in similar contexts.

\section{METHODS}

\section{Study site}

The Cau Hai Lagoon supports a multispecies capture fishery and low-intensity aquaculture through a diversity of habitats and a range of marine and brackish water conditions. The lagoon has had well-documented challenges related to overfishing due to technological intensification, a growing population of fishers, water stagnation related to density of fishing enclosures, and pollution from aquaculture and terrestrial runoff (e.g., Brzeski and Newkirk 2002, Marconi et al. 2010, Andrachuk and Armitage 2015). There have also been well-being issues stemming from poverty, lack of livelihood alternatives, unclear property rights, and historical exclusion of fishers from management institutions (e.g., DaCosta and Turner 2007, Tuyen et al. 2010, Boonstra and Nhung 2011).

Examination of livelihood and ecological challenges facing the Cau Hai Lagoon through the lens of property rights led to the recognition that customary fishery practices had relied on open access to common pool resources, and that modern technology, introduction of aquaculture, and increasing population density undermined the relevance of those customary practices (Tuyen et al. 2010, Huong and Berkes 2011). In response, a model for territorial use rights for fisheries (TURFs) was developed that was based on the formation of Fishing Associations (FAs), which could enter into comanagement agreements with local government agencies and receive allocations of collective property rights and responsibilities (Armitage et al. 2011, Marschke et al. 2012). Ostensibly, the intent of these arrangements are to (1) provide a mechanism for implementing and enforcing national and provincial fisheries laws, (2) set up institutions to enable fisher participation and some autonomy over monitoring and enforcement of fisheries laws and regulations, and (3) improve livelihoods for fishers.

The Phu Loc District government, which encompasses most of the lagoon, has moved forward with TURF allocations for all FAs in their district. As of 2014, the lagoon was demarcated into 16 fishing zones (Fig. 2 map shows demarcation according to communes; several zones have been further subdivided). The FAs receive bundles of exclusive rights for fishing and aquaculture and are responsible, through comanagement with commune governments, for monitoring and enforcing fisheries policies. Allocation of TURF rights to FAs followed a numbers of steps that are outlined in Table 1, including the signing of comanagement agreements with local government agencies. One of the requirements for FAs gaining TURF rights is to develop a fisheries management plan. These management plans set out goals for reducing gear, which was mandated by provincial laws. The management plans also give FA members an opportunity to contribute to the development of bylaws. 
Table 1. Steps and guidelines for the establishment of comanagement and allocation of collective property rights in the Cau Hai Lagoon.

\begin{tabular}{l}
\hline Steps \\
1. Formation of Fishing Associations (FAs) \\
2. Promote benefits of conservation \\
3. Assess status of lagoon resources \\
4. Capacity building for FAs and establishing bylaws
\end{tabular}

4. Capacity building for FAs and establishing bylaws

5. Plans for zoning within territory

6. Formation of comanagement

7. Application for rights allocation

8. Comanagement implementation
Guidelines

FAs form for respective lagoon territory. Membership must represent all types of gear users within the territory. Selection of chair, vice chair, and subcommittees.

University researchers, NGOs, and government agents lead workshops to educate fishers on the importance of fisheries conservation.

Gathering data on gear types in use and management practices within territory.

Training for FA leadership team. Development of management plan for territory and agreement on bylaws to regulate fishing activities. Determine criteria for access and use of resources and procedures for conflict resolution.

Mapping and plan for rezoning within territory for different gear use (fixed gear, mobile gear, and aquaculture), protection areas, and navigation waterways. Demarcation of zones in lagoon.

Formalization of partnerships for comanagement. Signatories typically include FA, commune government, Phu Loc District government. Application for rights allocation to FA can proceed once criteria are met for appropriate FA membership, formation of leadership team, and development of management plan. Applications are typically prepared on behalf of FAs by NGOs or university researchers who support the process. Rearrangement of aquaculture activities and fixed fishing gear (fish corrals). Ongoing monitoring of fishing activities and enforcement of laws and bylaws.
Fig. 2. Study sites in the Cau Hai Lagoon, Vietnam. Focal study sites were Vinh Giang commune (Giang Xuan Fishing Association) and Loc Binh commune (Loc Binh I Fishing Association). Map used with permission from Andrachuk and Armitage (2015).

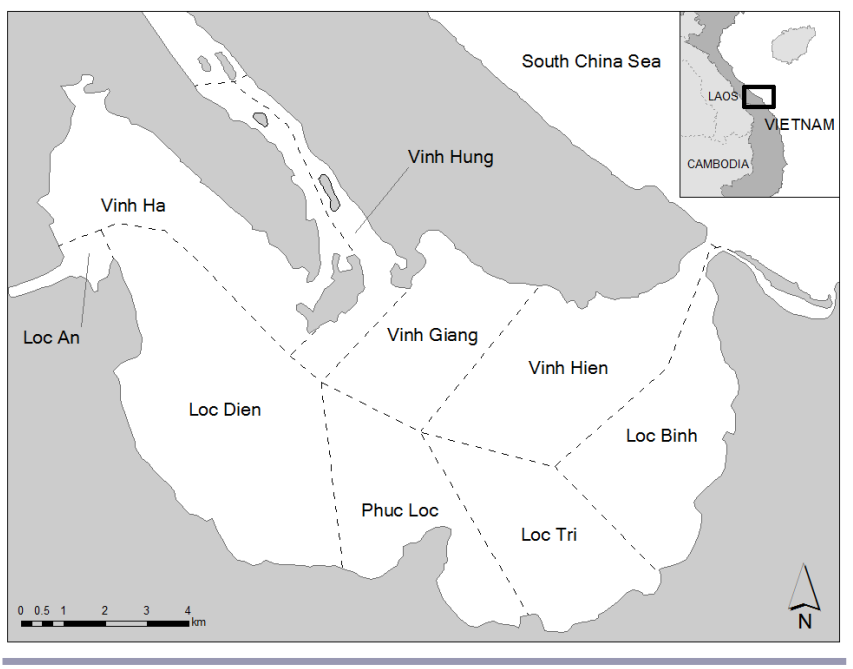

Andrachuk and Armitage (2015) used the concept of system identity to characterize past and current social-ecological transformations in the Cau Hai Lagoon. Drawing on the perspective of fishers to understand social and ecological changes, this research confirmed earlier reporting that ecological conditions have stabilized, and affirmed that a shift toward a new system identity may be underway as a result of the new governance arrangements (see also Tuyen et al. 2010, Armitage et al. 2011).
On the other hand, Andrachuk and Armitage (2015) also found that (1) minor improvements in fish catches have come at the cost of increased marginalization of some fishers, and (2) only a few of the FAs have been able to implement their management plans while most FAs are struggling to function.

Ho et al. (2016) have also discussed how the establishment of comanaged TURFs was donor-driven, which has led to limited "ownership" among some government comanagement partners. Ho et al. (2015) analyzed power sharing between government and FAs and the ability of fishers to exercise power in fisheries management. They found that although power sharing was intended in the design of comanagement, in practice, fishers are prevented from exercising powers due to lack of legal support and conflicting policies at higher levels of government (Ho et al. 2015). Boonstra and Hanh (2015) have also highlighted that many maladaptive and destructive practices, particularly for aquaculture, persist in the lagoon and contribute to a socialecological trap.

Taken together, this body of research has contributed to a better understanding of the interconnected issues facing the lagoon. More work is needed to identify pathways forward through adjustments to policies, redesigning interventions for improving livelihood, and building fisheries and aquaculture practices that are ecologically sustainable. Much of the forward-looking research on the lagoon has been aimed at policy and more general adjustments to SSF management. For instance, Armitage and Marschke (2013) suggested a series of policy responses: a more integrated approach to coastal systems, fishing, and aquaculture; clarification of the security of fishers' access rights to aquatic resources; and creating better conditions for multi-actor collaboration and learning. Andrachuk et al. (unpublished manuscript) advocated for better collaboration specifically between FA leaders, including resources devoted to supporting 
this collaboration. These assessments offer useful insights, but additional tangible and practical measures are also required to further actualize the gains being made.

The Cau Hai Lagoon presents a site where (a) governance and technological innovations are already in place, and (b) there is already evidence of success for some FAs. We work from the assumption that overcoming barriers to implementation of new SSF management - and hence supporting the transformationdoes not require additional social or technological innovations at this point. In consultation with Vietnamese research partners and local government, two communities were selected that are perceived to be functioning with high levels of success in terms of their ability to implement fisheries management plans: Vinh Giang commune (Giang Xuan FA) and Loc Binh commune (Loc Binh I FA). "Success" is used here to indicate that these FAs have been able to implement their fisheries management plans, engage members and hold regular meetings, collect membership fees, and consistently monitor and enforce regulations. While acknowledging that we did not develop an objective measure of success, we use the term as a relative comparison of these two FAs to the other 14 FAs in the Cau Hai Lagoon that have been unable to function adequately or implement their management plans. Our findings contrast the factors that have enabled the Giang Xuan and Loc Binh I FAs to function, thus supporting a nascent socialecological transformation (Armitage et al. 2011). This approach is intended to draw attention to the specific conditions that have been conducive to implementing comanagement and clarifying property rights. Because these FAs have been successful with implementing management strategies, there should be lessons of relevance for the other FAs. Scaling out these lessons among all FAs is needed given the interconnectivity of the lagoon socialecological system.

\section{Data collection and analysis}

Data were collected with the aim of facilitating a cross-case comparison within the Cau Hai Lagoon. Preliminary literature review and document analysis was carried out in order to review the context for efforts to implement comanagement and collective property rights in the Cau Hai Lagoon. A series of interviews were conducted with leaders of FAs in each of the case communities and with government agents in communes, district government, and provincial government $(n=16)$. The interviews followed a semistructured script, and attention was given primarily to the perceived purpose of comanagement and TURFs, challenges faced by FAs, and improvements observed for livelihoods and the lagoon environment. Focus groups with fishers were also held in each case community (total participants, $n=18$ ). The focus groups solicited discussion about what aspects of the new management arrangements fishers felt are working and what new challenges they are facing, and solicited their suggestions for management improvements. Two additional sets of interviews were conducted to follow up on specific issues. One set of interviews with key individuals $(n=4)$ was held in order to gather more information about conditions that contributed to FA success. A set of interviews with fishing households $(n=31)$ was used to solicit more local perspectives on the operation of the two successful FAs. Participant observation was also used to learn more about day-to-day fishing and aquaculture activities and the management issues facing FAs (e.g., conversations with fishers in their communities and taking boat tours with fishers).
Analysis followed a three-stage approach. First, we examined what it means for an FA to be successful following allocation of territorial use rights. Given strong capacity limitations in most FAs, this came down to whether FA members paid their fees and if FAs are able to fulfill their duties for monitoring and enforcement. These two factors were viewed internally by FA members and government agents as an indication that FAs were functioning according to their fisheries management plans. Evaluation of the case sites confirmed that research participants do believe the two FAs to be successful (see also Andrachuk and Armitage 2015). The second stage of analysis used a form of narrative categorization of interviews and focus groups that retained contextualization of data (Maxwell 2012). The findings in Case 1: Vinh Giang and Case 2: Loc Binh are the outcomes of this categorization and identification of factors that have been most important for FA success within each case. Third, we used a display-based technique (matrix) for comparing similarities and differences across the two main cases and interpreting common themes for FA success (Miles and Huberman 1994, Maxwell 2012). This cross-case comparison was the basis for identifying the building blocks and deriving lessons for what could be done to replicate successes for other FAs in the Cau Hai Lagoon.

\section{RESULTS}

We begin our findings with an examination of successes and limitations of new SSF management arrangements. The two highly functional FAs in the Cau Hai Lagoon are then reviewed indepth to identify the key factors that led to their success. Our intent has not been to identify identical building blocks in each case. Rather, we have sought to highlight the unique keys to successes for each FA to date. These key factors then form the basis of our synthesized building blocks for transformation pathways.

\section{Experiences with comanagement and collective property rights in the Cau Hai Lagoon}

Our interviews and focus groups revealed that there have been mixed signals from fishers and government about the implementation of TURFs. On one hand, fishers in all focus groups stated their preference for strengthening the ability of FAs to monitor activities in the lagoon and enforce policies. This was a demonstration of strong belief that the FA and TURF model can work. Fishers in the Cau Hai Lagoon are aware of the need for conservation and reduced fishing effort, but they are not able to envision a path to greater sustainability in a way that does not compromise their livelihoods and well-being. On the other hand, beyond some education workshops and rearrangement of fishing activity zones in the lagoon, there has been minimal implementation and enforcement of new policies. Water quality has improved to some degree, and the rate of fish catch decline has slowed, but there is a clear lag or stall in the social-ecological system transformation (Armitage et al. 2011, Andrachuk and Armitage 2015, Boonstra and Hanh 2015, Ho et al. 2016).

The capacity for FAs to undertake responsibility for their management functions has been a recurrent issue in SSF literature (e.g., Jentoft and Sandersen 1996). As we noted earlier, however, in the Cau Hai Lagoon, success relates as much to partnerships and collaboration as to management capacity. Before we discuss what has led to "success" for two Cau Hai Lagoon FAs (Case 1: Vinh Giang and Case 2: Loc Binh), we first highlight some 
Table 2. Cau Hai Lagoon building blocks and evidence for the building blocks in each subcase.

\begin{tabular}{|c|c|c|}
\hline Building blocks & Giang Xuan Fishing Association (FA) & Loc Binh I Fishing Association \\
\hline $\begin{array}{l}\text { Awareness of the value of ecological } \\
\text { conservation }\end{array}$ & $\begin{array}{l}\text { Workshops from university researchers and } \\
\text { international projects } \\
\text { Willingness of fishers to reduce gear and follow } \\
\text { new policies }\end{array}$ & $\mathrm{n} / \mathrm{a}$ \\
\hline Cooperation among fishers & $\mathrm{n} / \mathrm{a}$ & $\begin{array}{l}\text { Solidarity and trust among fishers } \\
\text { Cooperation with neighboring FAs to create } \\
\text { bylaws for habitat protection area }\end{array}$ \\
\hline Support from local government & $\begin{array}{l}\text { FA chairman communicates regularly with } \\
\text { commune government, leads to better } \\
\text { understanding of fisheries issues } \\
\text { Vice chair of FA is from police force }\end{array}$ & $\begin{array}{l}\text { Support from several key sympathetic individuals } \\
\text { within commune government }\end{array}$ \\
\hline Secure funding for the FA & $\begin{array}{l}\text { Membership fees collected from fishers } \\
\text { Salary for FA leader through employment with } \\
\text { commune government }\end{array}$ & $\begin{array}{l}\text { Microloan and credit system set up by fishers } \\
\text { Membership fees collected from fishers }\end{array}$ \\
\hline & & $\begin{array}{l}\text { Support from international projects to purchase } \\
\text { a computer and boat }\end{array}$ \\
\hline Good leadership within the FA & $\begin{array}{l}\text { Team of leaders willing to work together; meet } \\
\text { regularly to discuss issues for different fishing } \\
\text { gear users } \\
\text { Chairman has good communication and } \\
\text { organization skills }\end{array}$ & $\mathrm{n} / \mathrm{a}$ \\
\hline
\end{tabular}

apparent limitations that they face. Donor-led establishment of FAs and comanagement was often cited by FA leaders as valuable because NGO projects provided short-term access to funding and training. In some cases, project funding was used to purchase computers, boats, or other infrastructure. However, in most instances when projects ended, the management systems that were put in place collapsed. In several communities, fishers will not pay FA membership fees because they still see too much illegal fishing taking place, and they do not trust their FA leadership team. In addition to insufficient funding, FAs typically lack legal authority for enforcement against illegal fishing. District and commune governments were often cited as important organizations because FAs rely on them for any form of funding and support for fisheries patrols (monitoring lagoon activities).

Commune government officials and FA members are in agreement that provincial and district government policies to increase mesh size of nets are needed. However, implementation is hindered because many fishing households are poor, and even if they could afford new nets, there are few companies who produce nets with larger mesh. Limitations were also revealed in relation to training offered to fishers. During discussions with local university researchers, it was disclosed that when they give training presentations to fishers, they often do not consult with fishers about what they already know or how to present the information in a useful way. Fishers sometimes attend training sessions only because they receive money to participate. Fishers will often try new fishing and aquaculture techniques that they learn in these workshops (for instance, specific combinations of species to raise together for polyculture aquaculture), but if they do not see direct benefits or improvements, they will not stay committed.

How have some FAs been able to overcome these limitations? In the following sections we explore two successful cases.

\section{Case 1: Vinh Giang}

The Giang Xuan FA in Vinh Giang commune was established in 2008, and it received allocation of territorial use rights in 2009. The water area of the lagoon is 997 ha, of which 35 ha have been set aside for habitat protection (in 2010). One hundred, twentyfive households are FA members. In total, 102 households participate in aquaculture, although many of these households also participate in fixed and mobile gear fishing. In terms of fishing effort, FA members use 56 fish corrals (fixed gear) and an estimated 5700 lu nets (mobile gear), which are a form of bottom trap net with fine mesh.

Part of Vinh Giang's reputation as a successful case is due to its participation in a pilot project led by Vietnamese researchers at the Hue University of Agriculture and Forestry (HUAF) in partnership with Canadian researchers through the International Development Research Centre funding. This project tested the efficacy of FAs as an entity for comanaging TURFs and established the steps for rights allocations in Table 1. Positive reception in Vinh Giang led the district and provincial governments to create policies based on this model for other FAs to follow. Another important project was the Integrated Management of Lagoon Activities (IMOLA) project that worked across the entire Tam Giang - Cau Hai Lagoon. The Food and Agricultural Organization-funded IMOLA initiative had a key role in the zoning of TURFs and planning for rearrangement of fixed gear in the lagoon. According to our research, the projects did improve the capacity of the Giang Xuan FA leaders and the willingness of fishers to follow new fishing and aquaculture policies. For instance, FA leaders noted infrastructure capacity through the purchase of a computer, and management capacity through training for how the leadership team can work together. However, it is important to acknowledge that feasibility studies led to the selection of Vinh Giang for inclusion in those projects, meaning that there was underlying predisposition to cooperation in this commune. 
We have identified four key factors that appear to have led to this FA's success (Table 2). The first was the selection of an effective FA leadership team. The Giang Xuan FA chose people who have good communication and organizational skills, and also people who are able and willing to work well together. The leadership team has subgroup leaders to represent each group of fishersmobile gear fishers, fixed gear fishers, and aquaculture producers. These leaders meet regularly and share the experiences of their groups with each other. For instance, during seasons that are difficult for households who own fish corrals, the whole leadership team is made aware of specific challenges they are facing. Perhaps more importantly, according to our interviews with the FA chair, in the early stages of establishing TURF rights, all the FA leaders worked together to communicate with the commune government in order to foster good relationships. Interviews with commune officials reciprocated the importance of FA leaders - in particular the FA chair - for building positive relationships and trust.

The second key factor is support and cooperation from the commune government. There are several facets that contributed to sustained support. The FA chair regularly shares information with the commune government about FA activities. This has helped build mutual trust and understanding about fisheries issues. Additionally, the FA's vice chair is from the police, which helps the police force understand fisheries and aquaculture livelihoods and the importance of patrol teams for monitoring and enforcement. Commune government support means that there is good coordination and communication among all relevant local agencies for activities ranging from patrols to conflict resolution to consultation about creation of bylaws. For instance, one interviewee in government also explained how there is now accountability since there are people who are directly responsible for different aspects of fisheries management.

The third key factor is awareness among fishers about the importance of ecological conservation. The HUAF team initially helped fishers understand that protecting and conserving aquatic resources is in their interest for securing their livelihoods. In fact, several interviewees from the FA felt that this education was the most important contribution of external projects. Interviews with fishing households in Vinh Giang were unique in the ways that interviewees openly talked about the importance of reducing the number of nets used by households (especially Chinese lu bottom nets) and the benefits of increasing mesh size of fixed and mobile gear nets. Government interviewees also explained that prior to formation of the FA, Vinh Giang had many households that participated in (illegal) electric fishing. Government previously had no way to prevent or control use of this illegal activity. The combination of effective enforcement through coordinated efforts and buy-in from fishers on the need to reduce impacts on the lagoon thus led to a substantial decrease in electric fishing gear use.

Awareness about the importance of ecological conservation also led to fishers' willingness to set aside 35 ha for habitat protection and to participate in rearrangements of fixed gear. As discussed elsewhere (e.g., Marconi et al. 2010, Tuyen et al. 2010), the density of fish corrals in the lagoon through the early 2000 s caused water stagnation and algae blooms. Reduction and rearrangement of corrals in all FA zones in the lagoon have improved water flow and quality, and provided open waterways for navigation and reduced conflicts by establishing clear areas for fixed and mobile gear fishing.

The fourth key factor was funding to support the FA. Funding has meant that leaders are able to have some salary to compensate for their time and that the patrol team is able to pay for boats and fuel. Funding in Vinh Giang came initially from the externally funded projects and government, but continued funds come from members paying fees and from seaweed harvesting in the protection area. Considering that many other FAs around the Cau Hai Lagoon report that members refuse to pay fees, fisher participation in Giang Xuan FA (i.e., pay fees, attend meetings, follow bylaws) is an indication of trust. Access to funds has also helped the FA play a role in creating alternative livelihoods for FA members. Alternative livelihoods - tailored to each household based on their skills and wealth, and whether they have access rights to an area in the lagoon - have included new, less destructive gear for fishing, or training and infrastructure for new forms of aquaculture.

With good leadership, positive relationships with local government, awareness of conservation, and funding, the FA has been able to reduce conflicts between fishers who use different gear, reduce use of destructive fishing, regularly patrol the lagoon to enforce policies, and develop local rules (e.g., FA members get to vote to accept new bylaws; some other FAs do not do this). Furthermore, as one government official commented, the Giang Xuan FA is effective as a bridge between fishermen and government authorities.

\section{Case 2: Loc Binh}

Loc Binh commune has three FAs. We focus here on Loc Binh I FA. Of the other two FAs, one is concerned entirely with aquaculture and the other is smaller and not as well established. Loc Binh I FA was founded informally in 2003 when an entrepreneurial individual set up a microloan program. This individual is now the FA leader and has widespread trust and respect in this community and beyond. The FA received allocation of territorial use rights in 2010 and established a 40-ha protection area in 2011. The water area for this FA's zone is 987 ha. There are 100 FA members, of which 25 households participate in aquaculture (similar to Vinh Giang, some households participate in both fishing and aquaculture). Fishing effort in this FA includes 52 fish corrals and an estimated 6000 lu nets.

We have identified three key factors that have contributed to Loc Binh I FA's success (Table 2). First was funding to support FA activity. Primary among all factors for Loc Binh is a microloan program that was set up by fishers. In spite of not having financial training, the current FA leader was instrumental in the idea of fishers pooling their money in 2003 as a way to share and help each other through difficult years. In recent years, when difficult decisions had to be made to reduce the number of fixed fishing gear (corrals) to meet district government plans, FA leaders came to understand that some households would no longer be able to practice this type of fishing. The FA leaders worked with those households and discussed alternative livelihoods. Government provided some funding to those families, but the FA was also able to support them through microfinance loans to purchase new nets or other equipment. In an example that was discussed during a focus group, one man purchased a rototiller so that he could rent out his services to aquaculture pond owners while they were 
cleaning their ponds. The ability of FA members to access loans has been critical for building trust in the FA chairman and trust that their livelihoods will be supported. Interviews with Loc Binh commune officials - in addition to widespread acknowledgements from other communes - echoed the primacy and importance of the loan and credit system set up by the Loc Binh fishers. Additional financial support for Loc Binh I FA has also come through IMOLA and Fishery Livelihoods Project projects that provided workshops to teach fishers about the importance of ecological conservation, facilitate the establishment of a habitat protection area, and purchase a computer and boat to support FA activities.

The second key factor for Loc Binh was support from the commune government. In contrast to Vinh Giang, support from the local government appears to come from only a few influential people. The tone and content of interviews with those officials reflected an understanding of fisheries issues, and their support has been demonstrated through development of fisheries management plans and cooperation with the FA for enforcing fisheries policies. While emphasizing the importance of participation from all comanagement partners, there was evidence that the commune government's confidence and trust in the FA chairman is seen as very important for success of the FA.

Solidarity among fishers was the third key factor identified in Loc Binh. Fishing Association members are a close-knit community, in large part due to the sharing and trust discussed in relation to financial loans. During interviews with fishing households, there was an emphasis on personal relationships that help deal with livelihood challenges. Interviewees explained how they share information about skills (e.g., teaching each other about new aquaculture techniques), exchange observations about environmental conditions in the lagoon with neighbors who use the same gear, and receive help from family and neighbors to repair damaged gear. Fishing Association leaders have also worked closely with all fishers to understand problems faced by different gear users and to find solutions. For example, they work with contacts at the local fish market to find out prices for fish and then share this information with FA members so that they are aware of fair prices. Another way that fisher solidarity plays out is cooperation of the FA with neighboring FAs. This has included working with a neighboring FA to agree on bylaws for the habitat protection area, and coordinating patrols of the lagoon for enforcement against illegal fishing activities.

The outcome of secure funding, support from the commune government, and fisher solidarity has been similar to that of Vinh Giang. The Loc Binh I FA has been able to significantly reduce illegal fishing and overall fishing effort, carry out regular patrols of their lagoon zone, and support alternative livelihoods for members. The combination of solidarity and trust with an improved appreciation of the importance of conservation also made it easier to gain agreement on policies such as setting aside the protection area. Conflicts within this community were never as problematic as seen in other parts of the lagoon, although focus group participants did indicate that they now have few conflicts with fishers from outside of their community.

\section{DISCUSSION}

There is a need for practical strategies and grounded initiatives to foster ongoing transformation processes in SSF. We identified the need for an approach that was fine-grained for the local level and dealt with the potential to support a transformation that appears to be in progress. Through our earlier research (Tuyen et al. 2010, Armitage et al. 2011, Andrachuk and Armitage 2015) we saw signs of promise in the Cau Hai Lagoon, but there appeared to be a stall or lag following some initial promise. We advance the notion of building blocks as a way of thinking about and assessing supporting conditions for local-level transformations.

Facilitating deliberative social-ecological transformations for SSF implies the ability of actors to take actions that shift social and biophysical systems in new directions (Moore et al. 2014). Transformations and SSF literature have already indicated that social capital, appropriate legal settings, learning, and leadership are among factors that can contribute to such shifts (e.g., Olsson et al. 2008, Rijke et al. 2013, Benessaiah and Sengupta 2014, Cinner and McClanahan 2015). Nonetheless, there is a disconnect in finding ways to understand and shape those shifts in deliberative and proactive ways (Patterson et al. 2017). Our discussion aims to demonstrate some of the site-specific, forward-looking lessons that can emerge in useful ways to address these needs for SSF. Addressing persistent challenges for SSF requires grounded, bottom-up insights and building upon site-specific successes to facilitate continued and broader change. Moreover, the linkages and interactions among building blocks are also important, and may be responsible for creating the synergistic conditions that lead to transformation. This is an issue in need of further study.

\section{Synthesis of site-specific building blocks}

Our findings have explored what is working in two FAs in the Cau Hai Lagoon in order to understand why those FAs have been successful. We synthesized site-specific building blocks by distilling factors that contributed to the FAs' success (Table 2). Leadership and funding were identified as two of the key building blocks. However, we leave open the possibility for alternative and additional interpretations of building blocks. For instance, trust appears to be closely related to both leadership and funding. We interpreted the latter two as building blocks because they more directly capture the content of interviewee responses. Additionally, the other FAs in the Cau Hai Lagoon will likely each require a unique combination of building blocks. As noted in our basic attributes of building blocks, they are not to be thought of as static or linear. The approach of identifying context-specific factors is the prime interest. Different FAs are likely to require other building blocks that were not observed in Giang Xuan or Loc Binh I FAs (for example, bridging organizations, collective visioning, or poverty alleviation).

Fig. 3 is a graphic representation of five building blocks that emerged from the two cases: awareness of the value of ecological conservation, cooperation among fishers, support from local government, secure funding for the FA, and good leadership within the FA. We do not suggest that all five building blocks are required for success (or that these are the only potential building blocks), only that they provide insights and lessons for improving implementation of TURFs for SSF, and thus, improving ecological conditions and livelihoods in the Cau Hai Lagoon. It is noteworthy that although these building blocks were inductively identified through empirical research, they resonate with longstanding findings in literature on comanagement and SSF (e.g., Pinkerton 1989, Baland and Platteau 1996). 
Fig. 3. Building blocks for social-ecological transformation in the Cau Hai Lagoon. Dotted blocks suggest supporting conditions for transformation; the nonlinear arrangements of blocks along the pathway is a reminder that building blocks will not be the same for all Fishing Associations.

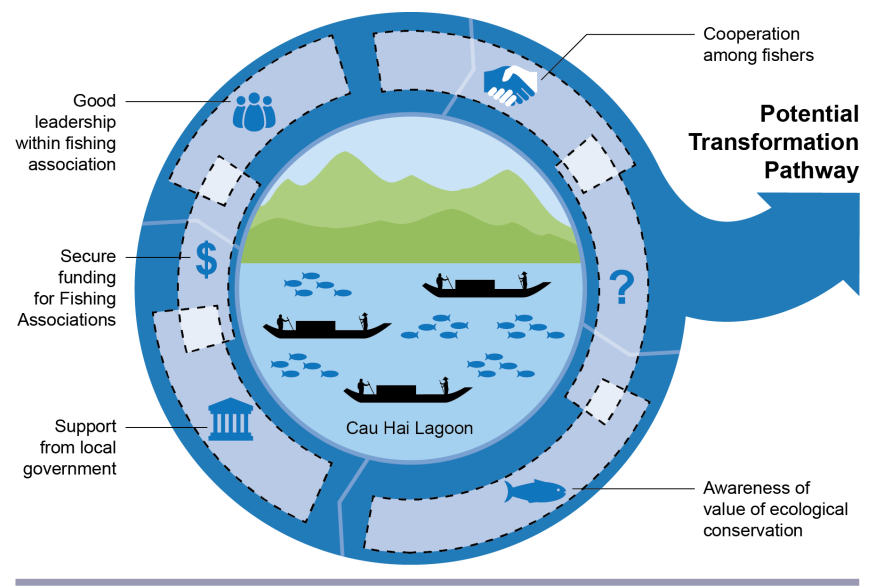

Deliberative transformations are complex and require many interconnected variables working together. Catalysts for the transformation also require acknowledgement. Innovations that helped set the Cau Hai Lagoon transformation in motion (Westley et al. 2011, Moore et al. 2014) were the introduction of FAs and comanaged TURFs. Fishing Associations replaced earlier attempts to create fisher cooperatives that were more politically oriented. The FAs have been adopted much more favorably by fishers because they reflect the organization of customary fisheries management. Territorial use rights for fisheries were introduced to deal with property rights issues that developed as a result of technological advances and growing population pressures. The legal and policy settings originated from the central government and opened the door for decentralized SSF management and comanagement with FAs (see also Tuyen et al. 2010, Armitage et al. 2011). Our aim here is not to describe all factors that initiated the transformation but to recognize and demonstrate how the factors build on each other and open opportunities for further interventions.

Each of the building blocks came about in different ways for the individual FA. Secure funding for both FAs was aided by the former presence of internationally funded projects, and both FAs collect membership fees. The main factor for Loc Binh I was their microloan system. Giang Xuan, on the other hand, greatly benefits from the FA chair receiving a salary from his participation in the commune government. Another building block that demonstrates differences in the ways that they took shape in each FA is support from local government. For Loc Binh I, that support comes from a few key individuals. Giang Xuan benefits greatly from strong communication by the FA chair that results in a better understanding of fishing issues for the commune government. These examples illustrate how supporting conditions for transformations can have different pathways. Our interpretation is that the building blocks have a presence in both FAs, but they are emphasized in different ways due to the ways that various factors are perceived to be important.
Up to this point we have focused attention only on FAs. In the following section, we consider what building blocks can reveal about support for FAs in ways that help build potential transformation pathways.

\section{Lessons for a transformation in progress}

The building blocks metaphor can be useful as a heuristic tool for reflection and learning. Several important lessons for Cau Hai Lagoon FAs follow from identification of building blocks. Specifically, these lessons indicate options for ways to enhance the success of other FAs, thus opening pathways for continuing the social-ecological transformation.

Improving implementation of comanaged TURFs should not focus only on FAs. The onus needs to be placed on all comanagement partners (i.e., commune and district governments) to be involved and committed to enforcing fisheries policies. There is a need for strong communication between FAs and commune government. Giang Xuan has shown the ideal standard, where the FA leader is both willing and has the opportunity to regularly share fishing experiences with government. The mutual understanding and trust developed through this communication has led to commune financial and physical support for activities such as lagoon monitoring and enforcement against illegal fishing practices. The comanagement arrangements require both authority and resources for implementation. As noted earlier, these types of lessons are consistent with the comanagement literature. However, the transformations literature is still developing site-specific lessons. The comanagement context adds a focus on governance processes and structures that can be instrumental to support a social-ecological transformation.

Among the steps for establishing comanagement (Table 1), it is not clear how step four (building capacity for FAs) was carried out in the case study FAs or other FAs. It is possible that Giang Xuan and Loc Binh I FA were fortunate to have good leadership and financial stability already in place, and the need for further capacity building was not essential. If that it is the case, it should have been imperative to add an additional step to develop a financial plan for each FA to ensure that they have financial stability. Furthermore, more consideration needs to be given to how FA leaders are selected and trained. Fishing Association members are fishers from poor communities who have had no training in SSF management or administration. A common attribute of leaders in the case FAs was their ability to gain trust and build relationships with both fishers and government.

The ability to navigate trade-offs is also critical for FAs. As fishers are required to reduce their number of gear-or remove all fixed gear for some households-transition plans and support for alternative livelihoods are needed. Fishers report fewer conflicts following rearrangement of fixed gear nets, but fishers who were already economically and politically marginalized are also more restricted in the fishing activities they can pursue (see also Andrachuk and Armitage 2015). Loc Binh I FA was able to work with members to create alternative livelihoods thanks to their microloan system and the commitment of FA leaders to meet members' needs. Fishing Association support came in the form of loans to purchase new nets, equipment, or training. In contrast, other FAs forced some households to share fish corrals because they had no way to financially support alternative livelihoods 
The network of fishers and government officials needs to be able to work together to overcome remaining social and ecological challenges facing the lagoon. These challenges include strong policy to reduce impacts from aquaculture, programs to divert household wastes from being dumped in the lagoon, better enforcement against destructive fishing practices, and further reduction of fishing effort by increasing mesh size of nets and reducing the total number of nets used (Armitage and Marschke 2013, Andrachuk and Armitage 2015, Ho et al. 2015). Outcomes of such actions remain uncertain, especially whether they will fulfill the social-ecological transformation, but these multifaceted challenges can be addressed only through collaboration.

We argue that the five building blocks we have identified have significant potential to contribute to improved implementation of comanaged TURFs for other Cau Hai Lagoon FAs. As literature on social-ecological transformations has shown (e.g., Leach et al. 2012, Moore et al. 2014), such empirical evidence of conditions that are conducive to success can lead to replication. For instance, because the process of establishing comanaged TURFs was donor driven, it undermined the participation of local government (Ho et al. 2016). The way that Giang Xuan FA was able to overcome this challenge was through continued and meaningful communication from the FA leader to government officials. This is a direct and practical lesson that can be shared with other FA leaders. Another lesson is that FAs - most likely with NGO, government, or researcher support-need to develop models of long-term funding. In Loc Binh I, a funding model was based on fisher-controlled loans. If these types of lessons were applied in other FAs, there would be a need for continued experimentation and learning (sensu Olsson et al. 2008). That is, these building blocks do not offer guarantees for success - they offer useful starting points for further experimentation and learning that is essential to support a long-term transformation.

Replicating successes, contributing to multilevel transformations We make two interrelated arguments with respect to governance of deliberative transformations. First, we need transformative change to proactively meet the well-being needs of people while eliminating ecologically unsustainable practices. However, we do not yet know enough about governance processes that support such transformations. Second, support for transformations requires continually building on successes. This does not preclude efforts to remove path dependencies and barriers to change, but focusing on what does work in situ can be more proactive and forward-looking.

We cannot know with certainty if the building blocks that we have identified, if applied in other Cau Hai Lagoon FAs, would generate the desired transformation outcomes. We do, however, have good reason to suspect that the lessons from the building blocks are likely to be transferable to other FAs in the lagoondue to the similarities within this SSF context - and improve implementation of comanaged TURFs. Commonalities across communities and FAs include dependence on the same resource base, the lagoon as an interconnected ecosystem, use of the same technologies for exploiting aquatic resources, similar levels of wealth, and immersion in the same political and legal settings. As we have noted earlier, the building blocks need not look identical for each FA. The building blocks are a reflection of what has been seen to work in two FAs and are likely to yield positive outcomes if they had been replicated during establishment of other FAs and comanagement agreements.

The notion of building blocks is not intended for scaling vertically. What they do reflect is a bottom-up perspective that can complement higher level, international efforts. Multilevel and multifaceted approaches have been advocated, but few approaches have been proposed for achieving these ends (Armitage et al. 2017, Patterson et al. 2017). Building blocks offer a metaphor and a heuristic that fills an important gap for governance. This idea of in situ, local-scale replication is novel in the transformations literature, where most work is at the global level. For SSF, this type of tool can be particularly useful because discussions about transformations are rarely about scaling up. The need for SSF is to find ways to support and build on very local, specific successes.

\section{CONCLUSION}

We introduced "building blocks" as an approach to assess local, fine-grained deliberative transformations, and to consider how to build transformative pathways. Complex social-ecological transformations - whether deliberative or emergent-require multiple building blocks. The intent is to seek out in situ the factors that can be built upon and replicated. We argue that such efforts to seek out supporting conditions are critical for research and action on deliberative transformations. This approach may be particularly useful for SFF because of the emphasis placed on local conditions and context-dependence.

We inductively analyzed potential building blocks in the Cau Hai Lagoon and assessed broadly applicable lessons. The small successes seen among two FAs in the lagoon contribute to a larger social-ecological transformation, but they need to be more than incremental or piecemeal. We offer some analysis of what has been working in those cases and hope that our efforts can help guide future research and development projects in the Cau Hai Lagoon. This research contributes to the growing body of literature on governance of deliberative transformations in SSF, and offers researchers a practical way to consider supporting conditions for such transformations.

\section{Responses to this article can be read online at: http://www.ecologyandsociety.org/issues/responses. php/10006}

\section{Acknowledgments:}

We thank communities and individuals where we worked for welcoming the research team into their homes and participating in our research. This work was made possible through funding from the International Development Research Centre (Ottawa, Canada) and the Social Sciences and Humanities Research Council of Canada. Thank you also to Jamie Kapitain for graphic illustrations.

\section{LITERATURE CITED}

Alexander, S. M., D. Armitage, and A. Charles. 2015. Social networks and transitions to co-management in Jamaican marine reserves and small-scale fisheries. Global Environmental Change 35:213-225. http://dx.doi.org/10.1016/j.gloenvcha.2015.09.001 
Allison, E. H., and F. Ellis. 2001. The livelihoods approach and management of small-scale fisheries. Marine Policy 25:377-388. http://dx.doi.org/10.1016/S0308-597X(01)00023-9

Andrachuk, M., and D. Armitage. 2015. Understanding socialecological change and transformation through community perceptions of system identity. Ecology and Society 20(4):6. http:// dx.doi.org/10.5751/ES-07759-200426

Armitage, D., S. Alexander, M. Andrachuk, S. Berdej, S. Brown, P. Nayak, J. Pittman, and K. Rathwell. 2017. Communities, multilevel networks and governance transformations in the coastal commons. Pages 231-251 in D. Armitage, A. Charles, and F. Berkes, editors. Governing the coastal commons: communities, resilience and transformation. Routledge, Abingdon, UK.

Armitage, D., and M. Marschke. 2013. Assessing the future of small-scale fishery systems in coastal Vietnam and the implications for policy. Environmental Science \& Policy 27:184-194. http://dx.doi.org/10.1016/j.envsci.2012.12.015

Armitage, D., M. Marschke, and T. V. Tuyen. 2011. Early-stage transformation of coastal marine governance in Vietnam? Marine Policy 35(5):703-711. http://dx.doi.org/10.1016/j.marpol.2011.02.011

Avelino, F., and J. Rotmans. 2009. Power in transition: an interdisciplinary framework to study power in relation to structural change. European Journal of Social Theory 12 (4):543-569.

Baland, J., and J. Platteau. 1996. Halting degradation of natural resources: Is there a role for rural communities? Food and Agriculture Association of the United Nations.

Benessaiah, K., and R. Sengupta. 2014. How is shrimp aquaculture transforming coastal livelihoods and lagoons in Estero Real, Nicaragua?: the need to integrate social-ecological research and ecosystem-based approaches. Environmental Management 54:162-179. http://dx.doi.org/10.1007/s00267-014-0295$\underline{\mathrm{X}}$

Blythe, J. L. 2014. Resilience and social thresholds in small-scale fishing communities. Sustainability Science 10(1):157-165. http:// dx.doi.org/10.1007/s11625-014-0253-9

Boonstra, W. J., and T. T. H. Hanh. 2015. Adaptation to climate change as social-ecological trap: a case study of fishing and aquaculture in the Tam Giang Lagoon, Vietnam. Environment, Development and Sustainability 17:1527-1544. http://dx.doi. org/10.1007/s10668-014-9612-Z

Boonstra, W. J., and P. T. H. Nhung. 2011. The ghosts of fisheries management. Journal of Natural Resources Policy Research 4:1-25. http://dx.doi.org/10.1080/19390459.2012.642634

Brzeski, V. J., and G. F. Newkirk, editors. 2002. Lessons in resource management from the Tam Giang Lagoon. Halifax, NS, Canada: Coastal Resources Research Network (CoRR).

Burch, S., A. Shaw, A. Dale, and J. Robinson. 2014. Triggering transformative change: a development path approach to climate change response in communities. Climate Policy 14(4):467-487. http://dx.doi.org/10.1080/14693062.2014.876342

Bush, S. R., and M. J. Marschke. 2014. Making social sense of aquaculture transitions. Ecology and Society 19(3):50. http://dx. doi.org/10.5751/ES-06677-190350
Carpenter, S. R., F. Westley, and M. G. Turner. 2005. Surrogates for resilience of social-ecological systems. Ecosystems 8:941-944. http://dx.doi.org/10.1007/s10021-005-0170-y

Chuenpagdee, R., and S. Jentoft. 2007. Step zero for fisheries comanagement: what precedes implementation. Marine Policy 31:657-668. http://dx.doi.org/10.1016/j.marpol.2007.03.013

Cinner, J. E., T. M. Daw, T. R. McClanahan, N. Muthiga, C. Abunge, S. Hamed, B. Mwaka, A. Rabearisoa, A. Wamukota, E. Fisher, and N. Jiddawi. 2012. Transitions toward co-management: the process of marine resource management devolution in three East African countries. Global Environmental Change 22 (3):651-658. http://dx.doi.org/10.1016/j.gloenvcha.2012.03.002

Cinner, J. E., and T. R. McClanahan. 2015. A sea change on the African coast? Preliminary social and ecological outcomes of a governance transformation in Kenyan fisheries. Global Environmental Change 30:133-139. http://dx.doi.org/10.1016/j. gloenvcha.2014.10.003

Crona, B., and O. Bodin. 2010. Power asymmetries in small-scale fisheries: a barrier to governance transformability? Ecology and Society 15(4):32. [online] URL: http://www.ecologyandsociety. org/vol15/iss4/art32/

DaCosta, E., and S. Turner. 2007. Negotiating changing livelihoods: the sampan dwellers of Tam Giang Lagoon, Viet Nam. Geoforum 38:190-206. http://dx.doi.org/10.1016/j. geoforum.2006.08.003

Fabinyi, M., S. Foale, and M. Macintyre. 2015. Managing inequality or managing stocks? An ethnographic perspective on the governance of small-scale fisheries. Fish and Fisheries 16:471-485. http://dx.doi.org/10.1111/faf.12069

Feola, G. 2015. Societal transformation in response to global environmental change: a review of emerging concepts. Ambio 44:376-390. http://dx.doi.org/10.1007/s13280-014-0582-z

Ferguson, B. C., R. R. Brown, and A. Deletic. 2013. Diagnosing transformative change in urban water systems: theories and frameworks. Global Environmental Change 23:264-280. http://dx. doi.org/10.1016/j.gloenvcha.2012.07.008

Frey, J. B., and F. Berkes. 2014. Can partnerships and communitybased conservation reverse the decline of coral reef socialecological systems? International Journal of the Commons 8 (1):26-46. http://dx.doi.org/10.18352/ijc.408

Gelcich, S., T. P. Hughes, P. Olsson, C. Folke, O. Defeo, M. Fernandeza, S. Foale, L. H. Gunderson, C. Rodriguez-Sickert, M. Scheffer, R. S. Steneck, and J. C. Castilla. 2010. Navigating transformations in governance of Chilean marine coastal resources. Proceedings of the National Academy of Sciences of the United States of America 107(39):16794-16799. http://dx.doi. org/10.1073/pnas.1012021107

Hahn, T., P. Olsson, C. Folke, and K. Johansson. 2006. Trustbuilding, knowledge generation and organizational innovations: the role of a bridging organization for adaptive comanagement of a wetland landscape around Kristianstad, Sweden. Human Ecology 34:573-592. http://dx.doi.org/10.1007/s10745-006-9035$\underline{\mathrm{Z}}$ 
Hauzer, M., P. Dearden, and G. Murray. 2013. The effectiveness of community-based governance of small-scale fisheries, Ngazidja Island, Comoros. Marine Policy 38:346-354. http://dx. doi.org/10.1016/j.marpol.2012.06.012

Heinmiller, B. T. 2009. Path dependency and collective action in common pool governance. International Journal of the Commons 3(1):131-147. http://dx.doi.org/10.18352/ijc. 79

Ho, N. T. T., H. Ross, and J. Coutts. 2015. Power sharing in fisheries co-management in Tam Giang Lagoon, Vietnam. Marine Policy 53:171-179. http://dx.doi.org/10.1016/j.marpol.2014.12.006

Ho, N. T. T., H. Ross, and J. Coutts. 2016. Evaluation of social and ecological outcomes of fisheries co-management in Tam Giang Lagoon, Vietnam. Fisheries Research 174:151-159. http:// dx.doi.org/10.1016/j.fishres.2015.09.013

Huong, T. T. T., and F. Berkes. 2011. Diversity of resource use and property rights in Tam Giang Lagoon, Vietnam. International Journal of the Commons 5(1):130-149. http://dx.doi.org/10.18352/ ijc. 236

Jentoft, S., and R. Chuenpagdee. 2015. Interactive governance for small-scale fisheries. Springer, MARE Publication Series, Switzerland. http://dx.doi.org/10.1007/978-3-319-17034-3

Jentoft, S., and H. T. Sandersen. 1996. Cooperatives in fisheries management: the case of St. Vincent and the Grenadines. Society \& Natural Resources 9:295-305. http://dx.doi.org/10.1080/08941929609380973

Leach, M., J. Rockström, P. Raskin, I. Scoones, A. C. Stirling, A. Smith, J. Thompson, E. Millstone, A. Ely, E. Arond, C. Folke, and P. Olsson. 2012. Transforming innovation for sustainability. Ecology and Society 17(2):11. http://dx.doi.org/10.5751/ ES-04933-170211

Marconi, M., M. Sarti, and F. Marincioni. 2010. Sustainability assessment of traditional fisheries in Cau Hai Lagoon (South China Sea). Marine Environmental Research 70:253-263. http:// dx.doi.org/10.1016/j.marenvres.2010.04.009

Marschke, M., D. Armitage, L. V. An, T. V. Tuyen, and H. Mallee. 2012. Do collective property rights make sense? Insights from central Vietnam. International Journal of the Commons 6(1):1-27. http://dx.doi.org/10.18352/ijc.334

Maxwell, J. A. 2012. A realist approach for qualitative research. Sage Publications, Washington, D.C., USA.

Miles, M. B., and A. M. Huberman. 1994. Qualitative data analysis: an expanded sourcebook. Sage Publications, Thousand Oaks, California, USA.

Moore, M.-L., O. Tjornbo, E. Enfors, C. Knapp, J. Hodbod, J. A. Baggio, A. Norström, P. Olsson, and D. Biggs. 2014. Studying the complexity of change: toward an analytical framework for understanding deliberate social-ecological transformations. Ecology and Society 19(4):54. http://dx.doi.org/10.5751/ ES-06966-190454

Nasuchon, N., and A. Charles. 2010. Community involvement in fisheries management: experiences in the Gulf of Thailand countries. Marine Policy 34:163-169. http://dx.doi.org/10.1016/j. marpol.2009.06.005
Nayak, P. K., D. Armitage, and M. Andrachuk. 2016. Power and politics of social-ecological regime shifts in the Chilika Lagoon, India and Tam Giang Lagoon, Vietnam. Regional Environmental Change 16(2):325-339. http://dx.doi.org/10.1007/s10113-015-0775-4

Nayak, P. K., and F. Berkes. 2014. Linking global drivers with local and regional change: a social-ecological system approach in Chilika Lagoon, Bay of Bengal. Regional Environmental Change 14:2067-2078. http://dx.doi.org/10.1007/s10113-012-0369-3

O'Brien, K. 2012. Global environmental change II: from adaptation to deliberate transformation. Progress in Human Geography 36(5):667-676. http://dx.doi.org/10.1177/0309132511425767

Olsson, P., Ö. Bodin, and C. Folke. 2010. Building transformative capacity for ecosystem stewardship in social-ecological systems. Pages 263-285 in D. Armitage and R. Plummer, editors. Adaptive capacity and environmental governance. Springer-Verlag, BerlinHeidelberg, Germany. http://dx.doi.org/10.1007/978-3-642-12194-4_13

Olsson, P., C. Folke, and T. Hahn. 2004. Social-ecological transformation for ecosystem management: the development of adaptive co-management of a wetland landscape in southern Sweden. Ecology and Society 9(4):2. http://dx.doi.org/10.5751/ ES-00683-090402

Olsson, P., C. Folke, and T. P. Hughes. 2008. Navigating the transition to ecosystem-based management of the Great Barrier Reef, Australia. Proceedings of the National Academy of Sciences of the United States of America 105(28):9489-9494. http://dx.doi. org/10.1073/pnas.0706905105

Olsson, P., V. Galaz, and W. J. Boonstra. 2014. Sustainability transformations: a resilience perspective. Ecology and Society 19 (4):1. http://dx.doi.org/10.5751/ES-06799-190401

Olsson, P., L. H. Gunderson, S. R. Carpenter, P. Ryan, L. Lebel, C. Folke, and C. S. Holling. 2006. Shooting the rapids: navigating transitions to adaptive governance of social-ecological systems. Ecology and Society 11(1):18. http://dx.doi.org/10.5751/ ES-01595-110118

Patterson, J., K. Schulz, J. Vervoort, S. van der Hel, O. Widerberg, C. Adler, M. Hurlbert, K. Anderton, M. Sethi, and A. Barau. 2017. Exploring the governance and politics of transformations towards sustainability. Environmental Innovations and Societal Transitions 24:1-16. http://dx.doi.org/10.1016/j.eist.2016.09.001

Pelling, M., K. O’Brien, and D. Matyas. 2015. Adaptation and transformation. Climatic Change 133:113-127. http://dx.doi. org/10.1007/s10584-014-1303-0

Pereira, L., T. Karpouzoglou, S. Doshi, and N. Frantzeskaki. 2015. Organising a safe space for navigating social-ecological transformations to sustainability. International Journal of Environmental Research and Public Health 12:6027-6044. http:// dx.doi.org/10.3390/ijerph120606027

Pinkerton, E. 1989. Cooperative management of local fisheries. University of British Columbia Press, Vancouver, British Columbia, Canada.

Pomeroy, R. S. 2012. Managing overcapacity in small-scale fisheries in Southeast Asia. Marine Policy 36:520-527. http://dx. doi.org/10.1016/j.marpol.2011.10.002 
Rijke, J., M. Farrelly, R. Brown, and C. Zevenbergen. 2013. Configuring transformative governance to enhance resilient urban water systems. Environmental Science \& Policy 25:62-72. http://dx.doi.org/10.1016/j.envsci.2012.09.012

Saunders, F. P., G. L. Gallardo-Fernandez, T. V. Tuyen, S. Raemaekers, B. Marciniak, and R. D. Plá. 2016. Transformation of small-scale fisheries - critical transdisciplinary challenges and possibilities. Current Opinion in Environmental Sustainability 20:26-31. http://dx.doi.org/10.1016/j.cosust.2016.04.005

Tuyen, T. V., D. Armitage, and M. Marschke. 2010. Livelihoods and co-management in the Tam Giang Lagoon, Vietnam. Ocean \& Coastal Management 53:327-335. http://dx.doi.org/10.1016/j. ocecoaman.2010.04.001

Weeratunge, N., C. Béné, R. Siriwardane, A. Charles, D. Johnson, E. H. Allison, P. K. Nayak, and M.-C. Badjeck. 2014. Small-scale fisheries through the wellbeing lens. Fish and Fisheries 15:255-279. http://dx.doi.org/10.1111/faf.12016

Westley, F., P. Olsson, C. Folke, T. Homer-Dixon, H. Vredenburg, D. Loorbach, J. Thompson, M. Nilsson, E. Lambin, J. Sendzimir, B. Banerjee, V. Galaz, and S. van der Leeuw. 2011. Tipping toward sustainability: emerging pathways of transformation. Ambio 40 (7):762-780. http://dx.doi.org/10.1007/s13280-011-0186-9

Westley, F. R., O. Tjornbo, L. Schultz, P. Olsson, C. Folke, B. Crona, and O. Bodin. 2013. A theory of transformative agency in linked social-ecological systems. Ecology and Society 18(3):27. http://dx.doi.org/10.5751/ES-05072-180327 